\title{
Compliance Dynamism: Capturing the Polynormative and Situational Nature of Business Responses to Law
}

\author{
Yunmei Wu ${ }^{1} \cdot$ Benjamin van Rooij ${ }^{2,3}$ (D)
}

Received: 8 October 2018 / Accepted: 8 June 2019 / Published online: 20 June 2019

(c) The Author(s) 2019

\begin{abstract}
Studying compliance, in terms of the business responses to legal rules, is notoriously difficult. This paper focuses on the difficulty of capturing the behavioral response itself, rather than on difficulties in explaining compliance and isolating particular factors of influence on it. The paper argues that existing approaches to capture such compliance, using surveys and governmental data, run the risk of failing to capture compliance as it occurs in the reality of day-to-day business responses to the law. It does so by means of a unique ethnographic approach to study compliance. Drawing from data of deep participant observation about responses to legal rules in two small businesses, the paper finds that in this context there is Compliance Dynamism. This means that compliance varies for different rules, it varies over time, and businesses learn from one response to the law to the next on a daily basis. Compliance is also situational, and there is an Indirect Observer Effect, where the way compliance is measured, especially when using data derived from inspections, shapes what compliance is observed and what is not. Therefore, compliance should be captured not as a singular state but as a string of reiterative processes that occur in their situational context. And this fundamentally challenges most existing methods to capture compliance and thus our understanding of what compliance occurs and what may shape it. In its conclusion, the paper draws out the implications this has for studies that seek to find simple and usable findings about compliance.
\end{abstract}

Keywords Compliance $\cdot$ Methods $\cdot$ Ethnography

\section{Introduction}

Compliance, under a broad definition, concerns the interactions between legal or social norms on the one hand and human and organizational behavior on the other (Van Rooij 2012). Now that compliance has become a vital concept in academic study and legal and regulatory practice, the measurement of compliance itself is of the utmost importance. Any discussion about whether punishment (Simpson et al. 2014; Nagin 2013), ethical codes (Kaptein 2011; Kaptein

Benjamin van Rooij

b.vanrooij@uva.nl

Yunmei Wu

65128947@qq.com

1 Yunnan Academy of Social Sciences, Kunming, Yunnan, People's Republic of China

2 School of Law, Amsterdam University, Amsterdam, Netherlands

3 School of Law, UC Irvine, Irvine, USA and Schwartz 2008), compliance management procedures (Krawiec 2003; Parker and Gilad 2011; Parker and Nielsen 2009c), whistle blower protection (Lee and Fargher 2013; Macey 2007; Moberly 2012; Near and Miceli 1995, 1996), procedural justice training (Tyler 1997, 2006; Tyler and Darley 1999; Nagin and Telep 2017), shaming (Van Erp 2008, 2011; Karpoff et al. 2008a, b; Braithwaite 1989), behavioral ethics (Feldman 2018) or social norms interventions (Cialdini 2007; Cialdini and Goldstein 2004; Gneezy and Rustichini 2000; Keizer et al. 2008, 2011) in the end boils down to understanding how targeted actors respond to the law. Because this entails studying illegal behavior, and behavior that is often not easily visible or observable it fundamentally challenges measurement and study.

The purpose of this paper is to focus on the challenge on how to measure compliance, and how best to capture how businesses respond to rules. It offers an ethnographic approach to capture compliance as behavioral responses to legal rules that occur in the day-to-day environment of small businesses. Here, it offers some important points of departure from existing approaches to compliance. The two most 
important approaches to study compliance use surveys or governmental data.

Survey compliance research uses either self-reported (e.g. Parker and Nielsen 2009b, c; Braithwaite 2003a; Braithwaite et al. 2007; Thornton et al. 2005) or factorial surveys (Fine et al. 2016; van Gelder and de Vries 2013; Van Rooij et al. 2017). These surveys allow for a good understanding of how actors that are targeted by the law themselves report how they have actually complied (in case of self-reported surveys) or would comply (in case of factorial surveys using vignettes). As such, their findings are generalizable to actual behavior, and because of the potential large number of respondents and relative low costs, they can be organized in a manner that is representative of a larger population. And upon using statistical analysis, the studies result in understandable and usable findings about particular influences on compliance. Factorial surveys using hypothetical scenarios that respondents are asked to respond to have the added benefit over self-reported behavioral surveys in that they can use experimental design and get to an understanding of causal mechanisms (cf. Rorie et al. 2018).

Another body of compliance work uses governmental data on regulatory offenses, derived from inspections or audits (e.g., Short and Toffel 2008; Ko et al. 2010). These studies have the same attractiveness as surveys in that they have large amounts of data concerning real actors and with similar statistical findings offering clear patterns and guidance on what shapes compliance. Their advantage over surveys is that the governmental data concern real violations of the law rather than self-reported or hypothetical ones. Their disadvantage is that governmental data only allow an insight into a limited amount of variables that may influence compliance and not into personal traits, perceptions, or cognitive or organizational processes of people whose compliance behavior is studied.

Existing compliance studies have a number of limitations. Self-reported surveys of compliance inherently suffer from a reporting bias due to self-presentation concerns, as respondents are reluctant to report on their illegal behavior (cf. Elffers et al. 1987, 1992, 2003; Elffers and Hessing 1997). Moreover, surveys asking about past conduct may suffer from a cognitive bias as people may simply not remember what they did exactly due to unawareness of their behavior at the time it occurred or memory decay (Elffers et al. 1987). Factorial surveys, while trying to overcome sensitivity by means of hypothetical scenarios, may still suffer from reporting bias, as respondents may not be willing to admit that they would engage in illegal behavior, even if it is hypothetical. Moreover, responding to hypothetical scenarios may not reflect actual behavior and thus lack in external validity (cf. Rorie et al. 2018).

Governmental data, finally, while not suffering from respondent biases, have their own inherent limitations in terms of accuracy. Many forms of regulatory compliance are hidden and hard to detect. Think, for instance, about tax evasion, accounting fraud, illegal pollution discharges, or occupation health violations. In cases where the compliance behavior is hard to discover and requires a strong inspection or audit capacity, the number of offenses found may not reflect the actual number of offenses that existed. And even worse, in case the compliance study seeks to understand the effect of inspections on compliance, its usage of inspection data as an indicator of compliance becomes endogenous, as compliance itself is measured through inspections.

The present study focuses on an unexplored and fundamental problem that existing approaches to capture compliance have-their focused and static nature. Surveys and governmental data allow only snapshots of the actual compliance processes as they take place in businesses on an everyday basis. Most surveys measure compliance only at one point in time, and with a focus on a few selected legal rules. And some surveys, with longitudinal design, may repeat questions a couple of times, a year or more after the first survey was conducted (e.g., Wenzel 2005; Gray and Scholz 1993). Governmental inspections and audits similarly focus on particular legal rules, with each type of government body being responsible for enforcing a particular set of rules, and with priorities for detecting higher risk violations. And due to limited inspection capacity, governmental data, while covering longer periods of time, only offer insights into compliance as it occurs on set intervals only when there were audits or inspections conducted.

The present study seeks to understand what happens when we use an ethnographic method to study compliance as it occurs on a daily basis within regulated businesses. This approach allows for an understanding of compliance from the bottom-up, which captures the behavioral responses to a multitude of legal rules as they occur over a prolonged period of time. This study will illustrate this ethnographic approach by analyzing data derived through a three-year study on participant observation carried out in two restaurants in China.

The core focus of the paper is thus methodological on understanding how we can capture compliance (business responses to the law). It does not focus on explaining compliance and analyzing the many potential influences on the behavioral responses we found. There is a thorough literature across criminology, psychology, organizational and management science, public administration, sociology, and anthropology, which addresses these issues, some of which we have highlighted at the start of this paper. The focus on capturing compliance is of course highly relevant for any study of influences on compliance, as it concerns the main dependent variable in such studies.

The study's core argument is that there is Compliance Dynamism. This means that compliance varies for different 
rules, it varies over time, and businesses learn from one response to the law to the next on a daily basis. Compliance is also situational, and there is an Indirect Observer Effect (similar to quantum physics), where observing compliance, especially by enforcement authorities, changes it. Methodologically, this means that compliance from this perspective should be captured not as a singular state but as a string of reiterative processes that occur in their situational context.

\section{Ethnographic Approaches and Methods}

This paper uses an ethnographic approach to study compliance. Here, it draws inspiration from the few earlier ethnographic compliance studies that exist (Lange 1999; Hutter 1997; Gray 2006, 2009; Heimer 1999; Falk Moore 1973; Vaughan 1997; Mascini and Wijk 2009). These studies show how complex compliance truly is, and how limited approaches that simply seek to understand compliance as a causal mechanism are between selected variables (i.e., deterrence, costs of compliance, social norms, and procedural justice) and measurements for law-abiding behavior.

This paper draws on three core insights into the nature of compliance from these ethnographic studies. The first is the recognition that compliance entails a plurality of norms and behaviors rather than just the simple matching of one particular behavior to one norm. The second is to see compliance as a process rather than as a static situation. The third insight is that compliance is not binary (in terms of violation or compliance) and is even hard to measure in a number, but rather requires capturing in language. Here we shall discuss these insights and how this paper intends to extend on them.

\section{First Extension: Capturing Compliance Behavior}

Ethnographic accounts of compliance show that the law will leave discretion and thus what becomes seen as compliance is a social construct based on interpretation and interaction by the regulator and regulated (Lange 1999; Hutter 1997). This is a fundamental critique on studies that seek to study compliance by looking at whether particular behavior conforms with a particular legal norm (Parker and Nielsen 2009a). In response to this critique, a body of qualitative studies have focused on how compliance processes shape the meaning of law (Talesh 2009, 2015; Edelman et al. 1991a; Edelman and Talesh 2011; Lange 1999). And while this is a very important question, it does move away from the behavior itself and the way through which the law may or may not shape behavior.

Here, we agree that compliance, especially as we study it here as a series of processes and involving multiple legal rules, cannot be captured in pre-determined binary notions of compliant or noncompliant or even gray scales along those lines. Yet we do not agree to then focus our study simply on how actors interpret the meaning of law (cf. Edelman 1992; Edelman et al. 1991b; Edelman and Talesh 2011; Lange 1999), and forget about behavior, or simply no longer qualify or label the behaviors found.

There are many legal rules that are not open for interpretation (Ubink 2008). For these rules, the issue is not so much to find out how they are interpreted and how regulatory interaction shapes the meaning of law. The core issue for studying compliance of businesses that face a multitude of such clear rules (as we do here) and whose behavior may change over time is to study the behavioral responses in a fine-grained manner as far as possible. So rather than determining a firm's compliance in overall binary terms compliance, or percentage of compliance, we propose to capture the behavioral responses as they occur for different rules at different points in time.

The resultant picture will evidently be complex, unless one simply wants to capture any firm that at any point for any rule has broken the law as noncompliant, which naturally will lead to most firms being seen as in violation. To allow for analysis and discussion, it is therefore vital to somehow group or capture such heterogeneous responses to the law. To develop such classification, we shall draw inspiration from work that has tried to characterize regulated actors and their motivations. We shall see for instance whether work on motivational postures that psychologically captures the different ways regulated actors respond to regulators and rules can be used to differentiate the nuances between the behavioral responses we see (for instance, whether we see a game-playing form of compliance, committed compliance, or resistant compliance) (Braithwaite et al. 1994, 2007). Moreover, we shall see whether we can capture the compliance behaviors by drawing on the classifications used in environmental governance studies to show the level of proactiveness that firms have in developing compliant management practices (Gunningham and Sinclair 2002). And finally, we shall look at whether classifications used for how people see the function of state regulators (Gray and Silbey 2014) can help us to classify the behavioral responses to legal rules.

All of this will then produce a more nuanced form to capture the nuance of compliance behavior, by capturing the different behaviors found in the regulated organizations in light of the legal rules as they are understood in practice, and second seeking to classify this complex of behaviors by means of the labels that capture the adjectives that describe the motivational context, proactiveness, and sort of relationship with regulators. All these things mean that the study of compliance must look beyond measurement and numbers, and also use language to capture compliance behaviors and processes as accurately as possible. 


\section{Second Extension: Polynormativism}

Existing compliance ethnographies also show the polynormative nature (cf. Riggs 1964; Griffiths 1986; Merry 1988; Von Benda-Beckmann 2006) of compliance, indicating that in reality there are many norms at play in shaping behavior. Sally-Falk Moore (1973) has, for instance, studied the influence of legal norms on behavior both in the case of the garment industry in New York City and coffee farmers in Tanzania. In both cases, she shows how the law's influence on the behavior is mediated through what she terms the Semi-Autonomous Social Field. With this, she indicates that the field that the behavior, which the law seeks to shape, exists in can itself "generate rules and symbols internally" (p. 720), and thus resist the influence of outside legal norms (Moore 1973).

Similarly, in her study of neonatal intensive-care units, Carol Heimer found that legally mandated institutions in hospitals tasked to implement the law had to compete with medical norms of the hospital staff, and familial norms of the families of children treated (Heimer 1999). She argued that in such competition, the medical hospital staff, because of their continued presence and experience for making relevant decisions, played the most important role in this rivalry. She found that hospital staff would only in earnest adopt legal norms that were directly useful to them, and would ignore or resist other legally mandated procedures and practices. For the legal procedures then to successfully influence the neonatal intensive care units, they had to adapt to the practices, interests, and even time-table of the hospital staff (Heimer 1999).

Or we can draw on Vaughan's detailed work of how organizational norms and values developed at NASA that created a "normalization of deviancy" that ultimately caused the Space Shuttle Challenger explosion (Vaughan 1997).

The second extension to the existing ethnographic compliance literature is the present study's deeper look at how a broader focus of relevant legal rules plays a role in the compliance processes. In most prior studies, polynormativity centered on the existence and interaction between a select legal norm and the social norms of the organization that it targeted (i.e., Moore 1973; Heimer 1999). Regardless of their rich and interpretative analysis, existing compliance ethnographies still mostly focus on understanding one set of particular legal norms (such as environmental rules, occupational health and safety, or land protection rules).

This study sees a broader form of polynormativity within the legal system itself. Nowadays with the development of highly complex regulatory legal systems people all face a multitude of legal rules that regulate their behavior. This is especially clear for businesses who must comply with laws, ranging from taxation to occupational health, from accounting to environmental protection. Polynormativism is not just a matter of the coexistence of legal and other norms, but also the coexistence of multiple legal norms. And these rules may well make conflicting demands. Maxwell et al. (2011) have, for instance, identified five sets of compliance requirements that appear to conflict in software compliance, most notably conflicts between the U.S. Health Insurance Portability and Accountability Act (HIPAA) and other laws. For instance, "under HIPAA, a covered entity may charge a reasonable, cost-based fee when providing copies of PHI to an individual, whereas in 29 CFR 1910.1020, employers must provide the first copy of an employee's medical record free of charge" (p. 204).

And as such, compliance does not entail the response to one particular legal rule but the response to a large number of legal rules. Just as there can be an interaction between a legal rule and the social and organizational norms that can resist it (Heimer 1999; Moore 1973), there can also be an interaction between how people and organizations respond to one rule and how they do to another. In a psychological study of rule violation, Keizer and colleagues, have shown that there is a contagion effect, where observing violation of one rule, also makes people more prone to violate another rule (Keizer et al. 2008). What we seek to understand here is similar but different, how do the experiences companies have in responding to one set of rules influence their responses to other rules. We expect that in these processes there will be learning effects, where our experiences with regard to one legal rule shape the way we think we must or can act in response to another.

\section{Third Extension: Compliance as process}

The existing ethnographic studies show compliance as a series of processes, most notably the encounters between regulators and regulated, during which they develop perceptions of each other (Mascini and Wijk 2009), during which games of hide and seek are played out as regulated actors learn to evade and obstruct (Gray and Silbey 2014), and during which regulators and regulated actors come to understand what is and what is not acceptable (Lange 1999; Hutter 1997). And while some have sought to try and find a sequence and order in such process trying to theorize steps from legal rule to final compliance decisions and behavior (Henson and Heasman 1998; Chemnitz 2012), we know that such clear linear sequence will often not exist as, for instance, social norms and existing behavior will shape how people understand what the law is and what it demands of them (Kim 1999; Darley et al. 2001).

This paper seeks to look deeper at the processual nature of compliance, by expanding the time frame of such processual analysis. Most studies of compliance processes focus on particular regulatory encounters between the regulated actor and the regulated (i.e., Mascini and Wijk 2009) or on 
the duration of the participant observation (i.e., Gray 2002, 2006, 2009). This study seeks to lengthen this time frame to analyze compliance behaviors and processes over the course of the business cycle, both during the initial start-up phase, as well as during daily operations during which the actual participant observation was conducted. In doing so, it moves beyond the study of the regulatory encounter, where regulated and regulators interact, and much deeper into the dayto-day behavioral responses as they occur in regulated firms, which has been much less researched. It does so through direct observation and interviews with managers, owners, and staff to learn what happened during the earliest days of compliance, and through direct observation and further interviews for the everyday operations after. This is a vital perspective as there are many legal demands that are only made and checked during the start-up phase when companies have to apply for permits and other licenses, which get much less scrutiny later in the business cycle. Also, there may be path dependencies that originate from the first compliance behaviors during this start-up process, which get to shape compliance down the road after it becomes fully operational. And finally, this approach allows us to understand what happens once a firm has achieved compliance and to what extent it can be maintained in day-to-day operations in which compliance may require reiterated efforts.

\section{Methods}

The present study uses a mixed-method qualitative research design. Its core method is that of the case study (Bennett and Elman 2006; Gerring 2004). The case study is used to get an in-depth understanding of the selected regulated actors, as they are studied as comprehensive cases to be understood in their operational complexity and their long-term historical context. The paper has selected two restaurants as objects of these case studies of compliance behavior. Restaurants were selected because they are typical of a small business organization that faces a myriad of rules, from business administration to taxation, from fire safety to food safety, from environmental protection to occupational health. Restaurants are also quite easily accessible and not too complex as organizations to create extra complications that would muddle the compliance analysis.

To gather data to understand compliance behavior in the case studied, this paper relies on two core methods. The first author conducted extensive participant observation (cf. Bernard 1995) by working as a waitress in both restaurants, with the explicit permission of the owner and workers to do so while conducting research. During the extensive period of study, over 3 years, from May 2011 to September 2013, she was able to observe in depth how different rules entered the business over a prolonged period of time and how owners, managers, and employees interacted with each other and with regulators in responding to these rules. Also through 26 in-depth semistructured as well as a multitude of short informal ethnographic interviews (cf. Bernard 1995; Bennett and Elman 2006), she gained data about the processes that had occurred in each business in its start-up phase to allow for an ever longer view on how compliance processes had occurred there. The data were recorded in meticulous fieldnotes, and then coded and analyzed to understand different behavioral responses to different rules over different periods of time.

The study has selected two restaurants in a provincial capital in South-Western China. This selection was done to understand compliance processes in cases that were similar in size and business operations, but had very different owners, business philosophies, and organizational cultures. During the extensive pilot period when extensive interviews were conducted with the owners of these two restaurants, it became apparent that their outlooks on their businesses were truly opposed. As such, within the subset of small restaurants in the city of study in China, these two restaurants present extreme cases (cf. Seawright and Gerring 2008), with one, an organic restaurant with an idealistic owner who cares about food safety and the environment, and the other a profit-maximizing owner who is always looking for ways to cut costs. Based on the extensive interviews with both owners the study has decided to label the first restaurant the Idealist and the second one the Profit-Maximizer. Using these labels makes it easier for readers to distinguish the two restaurants and the two business orientations that gave rise to them, as will be explained in more detail below when presenting the data about the two cases. One might think that by selecting these two cases and by labeling the two restaurants as such the study artificially stimulates the variability between these two cases. However, an analysis of the data, as presented below does the exact opposite, it shows that when viewing the full complexity of compliance responses as they occur in daily practice there are remarkable similarities between the two cases.

With this method, this study does not claim to generalize to a broad population of restaurants, let alone business or compliance in general. Rather it seeks to generalize conceptually, by highlighting how compliance processes take place when they are studied for a larger number of rules and over a longer period of time in two similar businesses with very different business strategies and moral outlooks, the moral-idealist versus the profit maximizing. It should be noted that the goal of the paper is not to understand how the differences between these two restaurants explain differences in compliance, but rather to see whether there are similar processes that play out in different type of restaurants (Ragin 1987). 


\section{Behavioral Complexity in Polynormative Compliance}

Our study covers two highly similar businesses, small restaurants in China, with very different leadership and business strategies. One, hereafter called the "Idealist," has an owner who is highly educated, and idealistic to provide healthy and good food. When she started her business the Idealist owner was committed to comply with the law and follow existing rules. The other restaurant, hereafter called the "Profit-Maximizer," has an owner who cares only about cutting costs in order to achieve the highest possible profit. The Profit-Maximizer owner was not committed to compliance when he started the business and was only interested in generating the most income possible. Yet, regardless of the differences in their leadership and their moral and legal commitments we find a variation of behaviors in both.

On the one hand, we see that the Idealist owner went out of her way to go further than what the law demanded. When she originally applied for her restaurant's environmental license, the Idealistic owner intentionally installed whole set of environmental protection facilities, including oil-smoke purification system and oil filter in the sewerage system, and the air capacity in oil-smoke purification system exceeded legal requirements to have a better capacity to purify oil-smoke. She bought more (six) fire extinguishers than the fire department required (four) when applying for the fire license. She also bought a high temperature disinfection cabinet that small and medium restaurants generally do not use due to high price, and which can disinfect dishware at over 120 Celsius to ensure proper extermination of germs. And once she got the appropriate licenses, she made sure that her restaurant did not just use cleaning agents that met food safety standards for disinfectants, but environmentally friendly organic products going beyond environmental regulatory requirements.

Therefore, as we might expect from the Idealist owner, these examples show a moral commitment to environmental protection and food safety that goes well beyond the law. They show a committed form of compliance (cf. Braithwaite 2003b; Braithwaite et al. 1994). They may lead us to believe that this particular restaurant will generally comply with the law because of the way the law matches the moral values and strategies of the owner. And as such one could, based on these first descriptions, try and label the Idealist restaurant as a "leader" (Gunningham and Sinclair 2002) that operates "beyond compliance" (Prakash 2001), or as "true believers" to the regulatory requirements (Kagan et al. 2003). And as such here seemingly, regulators are "allies" that aid the restaurant to achieve its goals of healthy and environmentally sound food (Gray and Silbey 2014).
However, this picture is not complete. Once we move away from these examples, and look at how the Idealist restaurant responded to other legal rules, we get a much more muddled picture. Once we bring in the fuller polynormative picture of behavioral responses to a broader array of legal rules, we find that the Idealist restaurant cannot be simply captured in one category of compliance. For instance, this well-intentioned restaurant, while consistently disinfecting small individual plates, failed to disinfect bigger tableserving plates, as the law clearly mandated. And while the Idealist restaurant did obtain a license for draining its waste water, it obtained this license only by using clean water, rather than ordinary drainage discharges, to pass the tests that were part of the application procedure. Moreover, the Idealist restaurant went as far as fabricating its disinfection $\log$ s to fool food safety inspectors when they came to verify legally mandated hygiene record keeping. The restaurant also used bought counterfeit quarantine certificates to attest that pork in the restaurant met the legal standards. And, although the Idealist tried to issue formal receipts to all customers as it is required to do so under taxation law, it would illegally reissue old receipts used earlier when they ran out of formal tax receipts due to spikes in business. The Idealist owner even tried to bribe fire safety regulators to obtain a fire license, under the false belief that only bribery would help them get that.

Therefore, here we get a very different picture of the Idealist restaurant. Rather than a committed complier, we see a business violates the law and engages in game playing and even outright resistance to the rules (Braithwaite 2003b), by fabricating and faking compliance. This is not the behavior of the good apple of the first examples, it is not the behavior of a leader but more of a laggard (Gunningham and Sinclair 2002). In the examples, the owner acts as if the regulators are threats and obstacles rather than allies (Gray and Silbey 2014).

The Profit-Maximizer restaurant shows a similarly muddled picture. As we would expect with an owner who cares only about reducing costs and increasing income, this business has tried to cut legal corners where it can. For example, the restaurant illegally underreported its number of employees to avoid higher cost when it applied for a business license that charges more for larger businesses. Similarly, it has underreported its revenue to evade tax when it applied for its tax license. The Profit-Maximizer bought fewer (two) fire extinguishers than legally mandated (six). And to still get its fire licensem it simply sent in staged photos that showed the right amount of fire distinguishers. And as another example of some of its fraudulent compliance behaviors, the Profit-Maximizer owner failed to send his employees to do the legally mandated health checks, and was able to still get them authentic health certificates obtained through his informal connections. It installed a smoke purifier when 
applying for its environmental license, but the purifier was not used in daily operations to purify the cooking smoke except when environmental inspectors would come on site. Similarly, the Profit-Maximizer never used the disinfection installations it was legally mandated to install and operate. The restaurant also obtained a catering services license and dutifully renewed it each year, yet it violated its conditions, for instance by serving cold dishes that it had not licensed. Just like the Idealist, the Profit-Maximizer also created a fake disinfection $\log$. It even faked its environmental license when it did not want to go through the trouble of renewing it. And because food safety inspectors never checked workers' nail hygiene compliance, employees illegally continued to flaunt long nails.

Yet at the same time we see many instances where even the Profit-Maximizer will follow legal rules. In part it does so simply because it is forced to do so. It renewed its liquor license only when inspectors came and threatened with punishment. The Profit-Maximizer also had instances where it did as the law and regulators would ask, even with limited threat of enforcement and still at considerable costs. The restaurant, for instance, replaced the old stone kitchen counter tops with a stainless steel one to successfully apply for a catering service license, rather than simply sending in a fabricated picture as it did for the fire extinguishers. The restaurant installed the oil filter and smoking purifier as required when it applied for its first environmental license. And each time, it would voluntarily renew its catering service license where it did not do so for the environmental license and liquor license.

So while clearly the Profit-Maximizer has much more fraudulent and fake compliance, more game playing and resistance (Braithwaite 2003b; Braithwaite et al. 1994) than the Idealist, we do also see that there is enforced compliance (Kirchler et al. 2008) and even some seemingly committed (Braithwaite 2003b; Braithwaite et al. 1994) and voluntary compliance (Kirchler et al. 2008) here. There is variation, depending on the rules at play, in how the restaurant sees the regulator, mostly either as obstacle or as threat (Gray and Silbey 2014). In sum, the Profit-Maximizer varies in how it responds to different rules, complicating labeling its behavior under any singular category as developed by the literature.

Our two cases also show that there can be variation in how a business responds to a single legal norm. This can happen when one legal norm covers several behavioral elements. For instance, to comply with the legal norm of obtaining a catering services license, a restaurant not only needs to install the required equipment and satisfy the required environmental conditions but also needs to ensure that all employees have valid health certificates. Both Idealist restaurant and the Profit-Maximizer fully complied with the first two elements of this legal norm, but fraudulently or partially complied with the third. Compliance regarding dish disinfection is another good example. At least three corresponding behaviors must be completed to comply with the disinfection norm: restaurants need to have and use equipment or tools (disinfection cabinet, disinfectant), disinfect all dishware (various spoons, bowls, dishes, chopsticks) before every use, and complete the disinfection log every time. However, while the Idealist restaurant went beyond compliance towards the first element here having better equipment than was needed, it only partially complied with the second, as it only used disinfection equipment for some dish ware and let alone others, and faked compliance with the third having fabricated logs. The Profit-maximizer did comply with the first element (as he had a disinfection cabinet and disinfectant), but partially violated the second, as it did offer some pre-packaged disinfected tableware but did not use the disinfection cabinet and disinfectant to disinfect other dishware, and faking compliance as it also fabricated its disinfection logs.

In sum, for these relatively small and simple businesses there is a variety of behavioral responses that vary across different legal rules, and even vary for behavioral elements of one single legal norm. Clearly, the Idealist restaurant tends to be more committed to the goals of the different legal rules and has shown more instances of going beyond what the law demands than the Profit-Maximizer. So, in comparison the Idealist could be labeled as more of a complier, more of a leader than the Profit-Maximizer. Yet even comparatively those labels would not be fair. Can we honestly call the Idealist restaurant a compliance leader if it purposely creates fake disinfectant logs to fool regulators? What we are left with is a muddled picture of behavioral complexity 'in a context of a plurality of legal norms, which is very much unlike how compliance is captured either in the simple binary terms compliant or violating and even in more subtle terms of motivational postures (Braithwaite 2003b; Braithwaite et al. 1994, 2007), levels of voluntariness (Kirchler et al. 2008), amount of regulatory commitment (Gunningham and Sinclair 2002) or types of regulator constructions (Gray and Silbey 2014).

\section{Compliance Metamorphosis}

Our analysis of these two restaurants covers a longer period of time. The ethnography was conducted over the course of 3 years in total. And through interviews, we were also able to construct how the restaurants responded to legal demands during the original starting of the business. What emerges from this longer time frame is a dynamic picture of compliance, as responses to the law in both restaurants changed. What we found is that even for the same legal norm and 
for the same behavioral element of such law, both cases we studied show changes over time.

There is a fundamental difference between compliance at the start-up phase when the business must meet legal requirements to get relevant operating licenses, and compliance in everyday operations once the business has opened. Businesses may fully comply with for obtaining all licenses to start, but then slip towards violating rules once daily operations start.

The Profit-Maximizer is a very good example. Consider for instance its compliance with Chinese environmental regulation. The restaurant installed all emission abatement equipment mandated by air pollution rules, including an expensive oil-smoke purifier. All, in order to obtain the environmental license it needed to start the restaurant. So during start-up it fully complied with environmental law. However, once it started business it simply did not switch on the oilsmoke purifier in its daily operations. The oil-smoke purifier became just a visible symbol to show its commitment to the environmental law but did not serve the substantial goal of the environmental law that is to reduce air pollution.

Later on, the Profit Maximizer decided to forego renewing its environmental license when it would lapse after 3 years, and just create its own counterfeit version using a counterfeit seal the owner had bought. So within 3 years the owner went from full compliance, to a form of optic compliance (Kluin 2014) having the installations and not using them, to a full fraudulent form of violation using the counterfeit license.

The Profit-Maximizer changed its compliance behavior after start-up for several reasons. First, the owner learned that he needed a real environmental license to start the business, most importantly to get other licenses such as business license and a catering service license. So start-up compliance was essential. Yet once in operation, the owner knew the environmental authorities would not carry out on-site inspections, as restaurant emissions are not a priority for the overworked regulators (Van Rooij 2006). Moreover, the owner expressed it: "the environmental license is just as a means for the Environmental Protection Bureau to generate income," and "anyway, they [the regulator] will give me the renewed environment license once I give them money" (NM05092013). Consequently, the owner never saw a true rationale for the license or for continued compliance with its mandates. Moreover, even with the slim chances of being discovered, he did not fear repercussions. He believed that he had grounds to sue the environmental regulators, should he be caught, for corruptly forcing restaurants like his to signing equipment cleaning contracts with a company that was the regulators had close relations with. So as a simple matter of cost-benefit calculation, the Profit-Maximizer simply saw that the benefits of saving costs on not using the equipment or paying for a real license renewal outweighed the risks of being caught and punished.

Compliance was also dynamic between start-up and daily operations at the Idealist. At the start-up phase the Idealist fully complied with all legal requirements to obtain a catering service license, including installing a sufficient number of sinks and ensuring that all employees have genuine health certificate following a health check. However, once the restaurant opened for business it decided to remove one sink that it did not need and that was taking up too much space in the kitchen. And when it hired new workers later, it sometimes did so without ensuring that they get a health check and a health certificate. This happened for instance when elderly workers were reluctant to get a health check, or for temporary workers such as interns who only plan to work in this restaurant for less than a few months, or when the manager was too busy to take employees to do health check.

Compliance for the same legal rules and behavioral elements in our two cases thus changed as businesses went from start-up to daily operations. Our case also provides evidence that compliance changed even within one phase of the business cycle, either during the start-up phase or daily operations.

Consider for instance how the Idealist applied for a fire license during the start-up phase. At first, it bought more fire extinguishers than legally required. But while waiting for the license application to be approved she became worried. And thus, based on what she had learned from other restaurant owners, she attempted to get the license illegally by bribing the inspectors. And as such, she moved from a beyond compliance license application to a strongly corrupting form of applying for this license. Ironically, the fire inspectors did not accept the bribe, but did issue the license nevertheless as the restaurant had met their standards. And thus, the case ended in compliance after all. Something similar happened when the Idealist tried to get a drainage license. When the owner applied she was in compliance with the legal requirements, yet to make sure she would get the license she attempted to bribe the inspectors over dinner. However, the bribe offered was deemed too low and the application was put on hold for almost a year. Through a contact at the drainage department she was able to finally get the procedure going again and was asked for a drainage water sample. As the owner was too worried not to pass the test, she decided send pure tap water rather than drainage water, and finally was issued the license. So in both cases here, both in start-up we see that what started as a compliant application, turned into attempts at bribery, and in the last case even outright fraudulent application. Here the start-up phase served as a process of learning, where the owner started out thinking that if all legal requirements are met the licenses will be 
ok, to learning (partly mistakenly) that bribing was necessary to obtain the licenses, to worrying that when this did not work only outright fraud would succeed.

Also, we find that compliance changes during the operational phase. A good example is how when there are inspections businesses may temporarily comply with the law. For instance, when inspectors asked the Profit-Maximizer to label the equipment and containers in the kitchen during one regular inspection tour in daily operation phase, the owner immediately followed and attached all equipment and containers with labels. And thus, he came in full compliance. However, once the inspectors were gone and operations resumed the labels were gradually washed away during regular cleaning. And without the direct pressure of the inspectors, the owner did not bother to attach the labels again. What we see here is that law enforcement itself creates the switches in compliance. When there are inspections there is more compliance, and once inspections end noncompliance comes back. Gray has captured this using the notion of Potemkin Villages, arguing that factories he studied would create the mirage of compliance, with managers and workers collaborating to show a compliant operation that was only there for show as long as the inspections were there (Gray 2002, 2006). Van Rooij has shown a similar process when studying polluting industry in China, which would only switch on its abatement equipment during the day when there could be inspections, and discharge without clean-up during the night when agents could not reach their premises (Van Rooij 2006).

The dynamics of compliance also occur when the opportunities for violation change (cf. Feldman 2018; Clarke 1980, 1995). A good example is how the Profit-Maximizer during the start-up phase complied with replacing its stone kitchen counter-top to obtain its catering services license. However, the owner later noticed that inspectors never came to inspect this change on-site. So, when he applied for the next permit, the fire license, he ensured from other restaurant owners that inspectors here would also not come on site. And, thus he seized the opportunity to save costs by simply sending in fake photos showing the legal amount of fire extinguishers. He only bought two fire extinguishers while six were legally required. Then he staged the two in three different positions in his restaurant and took photos of them to pretend that he bought six. Another example is how the idealist restaurant became compliant with the law's rules on pork quarantine certification. It used to slaughter pigs by itself and did not have authentic quarantine certification for their pork as legally required. Instead, it bought certificates illegally from other pork sellers. Later, because of the growing difficulty and cost of hiring a butcher, it gave up the traditional slaughter and sent their pigs to the official slaughter house. By doing so, it got authentic pork quarantine certificate legally and engaged in compliance.
In sum, compliance is not static, it changes both between business cycles and within the business cycle. A key factor of influence here is the amount of oversight towards compliance. When there is oversight there is more compliance, whether it is during start-up, which because of its clear behavioral nature (mostly verification of particular installations) is easier to oversee, or whether it is during the infrequent inspections that follow during operations, the restaurants either comply, or quite the opposite fake that they are in compliance. Enforcement oversight thus has two very different results. Either it can lead to a temporary form of compliance, or that may well change, as it did in the examples studied here, once enforcement is away. In these situations, we clearly have a situation that can be classified as "game playing" (Braithwaite 2003a, 2007; Braithwaite et al. 1994, 2007). And in cases where the extra oversight with more inspections results in fraudulent compliance, we can capture it as a form of "resistance" (Braithwaite 2003a, 2007; Braithwaite et al. 1994, 2007). In both situations, we see that the regulated actors see the regulators as threats or obstacles and not as allies (Gray and Silbey 2014).

A static analysis of compliance study would not capture this, especially if it measures compliance through enforcement data, as so many studies do. Such study would find firms to be in compliance at the moment of inspections. A dynamic form that recognizes the changes over a period of time will find a bleaker picture. Rather than a compliant firm, it will find companies that start to flaunt the rules even after experiencing enforcement. Rather than a deterrent effect of being inspected as some regulatory scholars would expect, we get quite the opposite, action during inspections to seem to be in compliance, followed by violations as soon as inspections are gone.

Law enforcement, in such as a situation, is backfiring. Rather than act as a deterrent that helps strengthen the norms of the law, what we see is that enforcement becomes part of fake and fraudulent processes, during which firms express their deep distrust of the law and establish deviant rather than compliant social norms, not just of breaking the regulatory rules, but also doing so in fake or fraudulent manners. And because of the dynamic nature of these processes, experience of faking or defrauding one inspection will shape actions later on with other regulatory norms and other regulators. This reminds us very much of the contagion effect Keizer and colleagues found in studies of negative effects of placing prohibition signs in environments where they were widely broken. Rather than establishing the norm of the prohibition, these signs backfired when regulated actors saw that they were widely broken, as the normative function of the signs overall was undermined (Keizer et al. 2011). Similarly in our cases, the experience with law enforcement, followed by violation of the law once inspectors left, undermines the legitimacy of both the enforcement and the 
broader normative system that is represented, and strengthens the social norm, the normalcy of deviance (Vaughan 1989, 1997).

\section{Discussion and Conclusion}

The ethnographic study of compliance produces a deeper and richer picture of how businesses respond to legal rules. Compared to existing compliance methods that have used surveys and governmental data, the ethnographic method used here allows for an understanding of compliance as it occurs across a larger number of legal rules and a longer period of time. This paper therefore makes an important methodological contribution. It does so in two parts. First it shows that through the ethnographic method a dynamic picture of compliance emerges. And second, it shows that such compliance dynamism presents a fundamental challenge for existing compliance methods.

To study the influence of law on organizational behavior, we must recognize that compliance is a dynamic phenomenon. Compliance concerns a multitude of legal norms, each with a multitude of behavioral elements, and for each of these with dynamic behavioral responses that can change over time. We found this at least to be the case in the two restaurants that we studied here. It is highly likely that these conclusions apply more broadly. Just like these restaurants many other businesses from small to larger will face a multitude of legal rules, and many of these legal rules will cover different forms of behavior, and the same contextual influences that created dynamism in the responses of the two restaurants, like the level of external oversight and lessons from experiences with regulators and competitors are likely at play elsewhere as well. Actually, we expect that compliance dynamism is likely more at play the larger the business is and the more complex the regulatory system is. So here, let us look again at what compliance dynamism actually means and what the implications are for the study of compliance.

First, compliance involves many different legal rules and for each rule potentially several behavioral aspects. In contrast to how compliance has mostly been studied, selfreported surveys and studies using inspection data, with a focus on particular legal rules or sets of legal rules, do not reflect the true nature of compliance for businesses. For businesses, the whole legal system with all its different sets of rules and multitudes of specific behavioral demands come to bear on them, coming with an overall cost, and demanding an overall response capacity which will influence their decisions to the different rules and behavioral norms separately. These rules may make competing or even conflicting demands. Moreover, firms will see these different rules in combination and their compliance decisions for one rule or sets of rules will come to affect compliance with others. Yet the way most existing compliance methods seek to measure compliance is mono-legal, with a focus on one set of rules (environmental, occupational health, taxes) or even singular legal rules within this broader set. They thus look at the company through a straw, and fail to see the comprehensive picture of legal demands that the company sees and responds to.

Second, compliance dynamism is related to time. We found here that there is a big difference between compliance during a business start-up and during regular operations. And even during regular operations, there can be big changes. We saw that the amount of oversight drives changes in compliance, as more oversight leads to temporary improvement, which can evaporate just as the oversight ends. A dynamic view on compliance shows that past regulatory experiences shape future behavioral responses and thus compliance is not just a behavioral response but also a process of learning. Most existing compliance measurement methods have either a one-off static view (most surveys), or use data that is collected at very particular times (during inspections).

Third, and closely related to our last point, compliance suffers from an indirect observer effect. In its dynamic nature, we saw that compliance changes when there is direct oversight (cf. Gray and Silbey 2014). In other words, observing compliance, as happens during inspections, changes it. The inspections induce a short-term improvement of compliance that ends when the inspections are over, This is relevant not just for law enforcement, but also for the study of compliance methodologically. When studies use data from government inspections, they must be aware how the very act of these inspections undermines the proper capturing of what happens in day-to-day business practices. If we want to move beyond self-reported methods to study real or hypothetical compliance, we must come to observe it, whether through using inspection data, direct observations in field experiments, or as we did here through ethnography. In all these instances, we must be aware that observation in of itself may change what we seek to observe. In quantum mechanics, this was originally dubbed "the observer effect," and in social and behavioral science the Hawthorne effect (cf. Adair 1984). When inspections do not just capture compliance but also obscure true compliance practices, using such inspection data means that research suffers from an indirect observer effect where the researcher uses observations that have obscured the subject of research. So far it has been applied only in studies of compliance in medical settings (cf. Eckmanns et al. 2006), but not yet more broadly to the overall study of compliance, we believe it is crucial for. The indirect observer effect will vary, we think, depending on how bad the illegal behavior is seen to be, how aware the regulated actor is to the observation, how much trust the 
regulated has in the observer, and how normal and regular the observation has become. The ethnographic method will have the disadvantage that regulated actors will know they are directly observed, but the advantage that trust and normalcy can be established that can reduce the observer effect.

Of course, following the endogenous compliance scholars (Edelman 1992; Edelman et al. 1991a; Edelman and Talesh 2011; Lange 1999) there is a further complexity to compliance that we have not addressed in this study, and this is the plurality of legal interpretation. A singular legal rule may have different meanings for different actors and undermine any uniform measurement in practice, and rather the compliance process of interactions between regulators and regulators comes to shape the meaning of the law itself, rather than giving clear guidance on the effectiveness of law to shape behavior.

Our second core conclusion is that compliance dynamism forms a fundamental methodological challenge for existing compliance research. The core problem is that the polynormative and situational nature of compliance defies the existing static forms of measurement. Most of the popular existing measures of compliance offer limited snapshots of particular behavioral responses to particular legal rules at a particular point in time. Moreover, measurements themselves may shape the compliance behavior, especially if they are done as part of law enforcement inspections or internal compliance management. Such measures will create more compliance during the snapshot and for the rules targeted, and less so outside of their limited scope of focus and time frame. As the field of compliance management practice professionalizes, there will be increasing calls to evaluate success or failure, and this will likely make measurement more important not just in academia but also in practice. However, there is a real danger that this will result in ever simpler and more costeffective methods to measure compliance, and less likely to match the true dynamic nature of compliance we have captured here.

Fine and Elsbach have shown that social science methods generally make a trade-off between accuracy, generalizability and simplicity (Fine and Elsbach 2000). This is highly relevant for compliance research. Getting accurate data about whether people or organizations are breaking the law is highly difficult. And the situations in which it is possible to observe such behavior are either artificial (such as in laboratory experiments) or highly particularistic (such as in field experiments or ethnography) and thus not easily generalizable to reality in general or different realities. Moreover, the more accurate the knowledge becomes and the more linked it becomes to the reality of actual behavior, the less likely it can easily be captured in simple terms such as compliant or noncompliant, and the more it will result in complex findings. We hold that compliance research has too long valued generalizability and simplicity over accuracy.

Our core conclusion is that compliance dynamism requires a move away from just focusing the measurement of compliance, to also capturing compliance in its dynamic complexity. Compliance dynamism requires a comprehensive response. One that sees compliance across legal domains, over a longer period of time, and through multiple interpretations of the law. Compliance dynamism also requires a new way of characterizing and classifying the regulated actors. Existing ways that classify them based on their motives of noncompliance (Kagan and Scholz 1984), or motivational postures (Braithwaite et al. 1994; Braithwaite 2003b), or management styles (Kagan et al. 2003), or amount of regulatory commitment (Gunningham and Sinclair 2002) fail to account for the regulated actors' complex and dynamic responses satisfyingly. The context of compliance dynamism requires a more fine-grained and multifaceted characterization that classifies regulated actors and that fits the polynormative and situational nature of compliance we have found here.

\section{Compliance with Ethical Standards}

Conflict of interest Benjamin van Rooij has received research grants from the Netherlands Scientific Organization. There are no conflicts of interest between these grants and the study submitted here.

Ethical Approval All procedures performed in studies involving human participants were in accordance with the ethical standards of the institutional and/or national research committee and with the 1964 Helsinki declaration and its later amendments or comparable ethical standards.

Informed Consent Informed consent was obtained from all individual participants included in the study.

Open Access This article is distributed under the terms of the Creative Commons Attribution 4.0 International License (http://creativeco mmons.org/licenses/by/4.0/), which permits unrestricted use, distribution, and reproduction in any medium, provided you give appropriate credit to the original author(s) and the source, provide a link to the Creative Commons license, and indicate if changes were made.

\section{References}

Adair, J. G. (1984). The Hawthorne effect: A reconsideration of the methodological artifact. Journal of Applied Psychology, 69(2), 334.

Bennett, A., \& Elman, C. (2006). Qualitative research: recent developments in case study methods. Annual Review of Political Science, 9, 455-476.

Bernard, H. Russell. (1995). Research methods in anthropology, qualitative and quantitative approaches. Walnut Creek: Altamira Press.

Braithwaite, J. (1989). Crime, shame and reintegration. Cambridge: Cambridge University Press. 
Braithwaite, V. (2003a). Tax system integrity and compliance: The democratic management of the tax system. In V. Braithwaite (Ed.), Taxing democracy: Understanding tax avoidance and evasion (pp. 271-290). Aldershot: Ashgate Publishing Ltd.

Braithwaite, V. (Ed.). (2003b). Taxing democracy. Aldershot: Ashgate Publishing Ltd.

Braithwaite, V. (2007). Responsive regulation and taxation: Introduction. Law and Policy, 29(1), 3.

Braithwaite, V., Braithwaite, J., Gibson, D., \& Makkai, T. (1994). Regulatory styles motivational postures and nursing home compliance. Law \& Policy, 16(4), 363-394.

Braithwaite, V., Murphy, K., \& Reinhart, M. (2007). Taxation threat, motivational postures, and responsive regulation. Law \& Policy, 29(1), 137-158.

Chemnitz, C. (2012). The impact of food safety and quality standards on developing countries agricultural producers and exports. Berlin: Landwirtschaftlich-Gärtnerische Fakultät, HumboldtUniversität zu Berlin.

Cialdini, R. B. (2007). Descriptive social norms as underappreciated sources of social control. Psychometrika, 72(2), 263-268. https ://doi.org/10.1007/s11336-006-1560-6.

Cialdini, R. B., \& Goldstein, N. J. (2004). Social influence: Compliance and conformity. Annual Review of Psychology, 55, 591621. https://doi.org/10.1146/annurev.psych.55.090902.142015.

Clarke, Ronald V. G. (1980). Situational crime prevention: Theory and practice. The British Journal of Criminology, 20(2), $136-147$.

Clarke, R. V. (1995). Situational crime prevention. Crime \& Justice, 19, 91-150.

Darley, J. M., Carlsmith, K. M., \& Robinson, P. H. (2001). The ex ante function of the criminal law. Law and Society Review, 35, $165-190$.

Eckmanns, T., Bessert, J., Behnke, M., Gastmeier, P., \& Rüden, H. (2006). Compliance with antiseptic hand rub use in intensive care units the Hawthorne effect. Infection Control and Hospital Epidemiology, 27(9), 931-934.

Edelman, L. B. (1992). Legal ambiguity and symbolic structures: Organizational mediation of civil rights law. American Journal of Sociology, 97(6), 1531-1576.

Edelman, L. B., Petterson, S., Chambliss, E., \& Erlanger, H. S. (1991a). Legal ambiguity and the politics of compliance: Affirmative action officers' Dilemma. Law \& Policy, 13(1), 73-97.

Edelman, L. B., Petterson, S., Chambliss, E., \& Erlanger, H. S. (1991b). Legal ambiguity and the politics of compliance: Affirmative action officers' dilemma. Law \& Policy, 13(1), 73-97.

Edelman, L. B., \& Talesh, S. A. (2011). To comply or not to complythat isn't the question: How organizations construct the meaning of compliance. In Nielson Vl (Ed.), Parker C (pp. 103-122). Cheltenham: Explaining compliance business responses to regulation. Edward Elgar Publishing.

Elffers, H., \& Hessing, D. J. (1997). Influencing the prospects of tax evasion. Journal of Economic Psychology, 18(2), 289-304.

Elffers, H., Robben, H. S., \& Hessing, D. J. (1992). On measuring tax evasion. Journal of Economic Psychology, 13(4), 545-567.

Elffers, H., van der Heijden, P., \& Hezemans, M. (2003). Explaining regulatory non-compliance: A survey study of rule transgression for two Dutch instrumental laws, applying the randomized response method. Journal of Quantitative Criminology, 19(4), 409-439.

Elffers, H., Weigel, R. H., \& Hessing, D. J. (1987). The consequences of different strategies for measuring tax evasion behavior. Journal of Economic Psychology, 8(3), 311-337.

Falk Moore, S. (1973). Law and social change: The semi-autonomous social field as an appropriate subject of study. Law \& Society Review, 7(4), 719-746.
Feldman, Y. (2018). The law of good people: Challenging states' ability to regulate human behavior. Cambridge: Cambridge University Press.

Fine, A., Van Rooij, B., Feldman, Y., Shalvi, S., Leib, M., Scheper, E., et al. (2016). Rule orientation and behavior: Development and validation of a scale measuring individual acceptance of rule violation. Psychology, Public Policy, and Law, 22(3), 314-329.

Fine, G. A., \& Elsbach, K. D. (2000). Ethnography and experiment in social psychological theory building: Tactics for integrating qualitative field data with quantitative lab data. Journal of Experimental Social Psychology, 36(1), 51-76.

Gerring, J. (2004). What is a case study and what is it good for? American Political Science Review, 98(2), 341-354.

Gneezy, U., \& Rustichini, A. (2000). Fine is a price, A. The Journal of Legal Studies, 29, 1.

Gray, G. C. (2002). A socio-legal ethnography of the right to refuse dangerous work. Studies in Law, Politics, and Society, 24, 133-169.

Gray, G. C. (2006). The regulation of corporate violations punishment, compliance, and the blurring of responsibility. British Journal of Criminology, 46(5), 875-892.

Gray, G. C. (2009). The responsibilization strategy of health and safety neo-liberalism and the reconfiguration of individual responsibility for risk. British Journal of Criminology, 49(3), 326-342.

Gray, W., \& Scholz, J. T. (1993). Does regulatory enforcement work? A panel analysis of OSHA enforcement. Law \& Society Review, 27(1), 177-213.

Gray, G. C., \& Silbey, S. S. (2014). Governing inside the organization: Interpreting regulation and compliance. American Journal of Sociology, 120(1), 96-145.

Griffiths, J. (1986). What is legal pluralism? Journal of Legal Pluralism, 24, 1-50.

Gunningham, N., \& Sinclair, D. (2002). Leaders and laggards, next-generation environmental regulation. Sheffield: Greenleaf Publishing.

Heimer, C. A. (1999). Competing institutions: Law, medicine, and family in neonatal intensive care. Law \& Society Review, 33(1), 17-66.

Henson, S., \& Heasman, M. (1998). Food safety regulation and the firm: understanding the compliance process. Food Policy, 23(1), 9-23.

Hutter, B. M. (1997). Compliance: Regulation and environment. Oxford: Clarendon Press.

Kagan, R. A., \& Scholz, J. T. (1984). The "criminology of the corporation" and regulatory enforcement strategies. In K. Hawkins \& J. M. Thomas (Eds.), Regulatory enforcement (pp. 67-95). Boston: Kluwer-Nijhoff Publishing.

Kagan, R. A., Gunningham, N., \& Thornton, D. (2003). Explaining corporate environmental performance: How does regulation matter? Law \& Society Review, 37(1), 51-90.

Kaptein, M. (2011). Toward effective codes: Testing the relationship with unethical behavior. Journal of Business Ethics, 99(2), 233-251.

Kaptein, M., \& Schwartz, M. S. (2008). The effectiveness of business codes: A critical examination of existing studies and the development of an integrated research model. Journal of Business Ethics, $77(2), 111-127$

Karpoff, J. M., Scott Lee, D., \& Martin, G. S. (2008a). The consequences to managers for cooking the books. Journal of Financial Economics, 88(88), 193-215.

Karpoff, J. M., Scott Lee, D., \& Martin, G. S. (2008b). The cost to firms of cooking the books. Journal of Financial and Quantitative Analysis, 43(03), 581-611.

Keizer, K., Lindenberg, S., \& Steg, L. (2008). The spreading of disorder. Science, 322(5908), 1681-1685.

Keizer, K., Lindenberg, S., \& Steg, L. (2011). The reversal effect of prohibition signs. Group Processes \& Intergroup Relations, 14(5), 681-688.

Kim, P. T. (1999). Norms, learning and law: Exploring the influences of workers' legal knowledge. University of Illinois Legal Review, 1999(2), 447-516. 
Kirchler, E., Hoelzl, E., \& Wahl, I. (2008). Enforced versus voluntary tax compliance: The "slippery slope" framework. Journal of Economic Psychology, 29(2), 210-225.

Kluin, M. H. A. (2014). Optic compliance: enforcement and compliance in the Dutch chemical industry. Ridderkerk: Ridderprint.

Ko, K., Mendeloff, J., \& Gray, W. (2010). The role of inspection sequence in compliance with the US Occupational Safety and Health Administration's (OSHA) standards: Interpretations and implications. Regulation \& Governance, 4(1), 48-70.

Krawiec, K. D. (2003). Cosmetic compliance and the failure of negotiated governance. Wash. ULQ, 81, 487.

Lange, B. (1999). Compliance construction in the context of environmental regulation. Social \& Legal Studies, 8(4), 549-567.

Lee, G., \& Fargher, N. (2013). Companies' use of whistle-blowing to detect fraud: An examination of corporate whistle-blowing policies. Journal of Business Ethics, 114(2), 283-295.

Macey, J. (2007). Getting the word out about fraud: A theoretical analysis of whistleblowing and insider trading. Michigan Law Review, 105, 1899-1940.

Mascini, P., \& Wijk, E. V. (2009). Responsive regulation at the Dutch Food and Consumer Product Safety Authority: An empirical assessment of assumptions underlying the theory. Regulation \& Governance, 3(1), 27-47.

Maxwell, J. C, Antón, A. I., \& Swire, P. (2011). A legal cross-references taxonomy for identifying conflicting software requirements. Requirements Engineering Conference (RE), 2011 19th IEEE International.

Merry, S. E. (1988). Legal pluralism. Law and Society Review, 22(5), 869-896.

Moberly, R. (2012). Sarbanes-Oxley's whistleblower provisions: Ten years later. SCL Review, 64, 1.

Moore, S. F. (1973). Law and social change: The semi-autonomous social field as an appropriate subject of study. Law \& Society Review, 7, 719-746.

Nagin, D. S. (2013). Deterrence in the twenty-first century. Crime and Justice, 42(1), 199-263.

Nagin, D. S., \& Telep, C. W. (2017). Procedural justice and legal compliance. Annual Review of Law and Social Science, 13, 5-28.

Near, J. P., \& Miceli, M. P. (1995). Effective-whistle blowing. Academy of Management Review, 20(3), 679-708.

Near, J. P., \& Miceli, M. P. (1996). Whistle-blowing: Myth and reality. Journal of management, 22(3), 507-526.

Parker, C., \& Gilad, S. (2011). Internal corporate compliance management systems: Structure, culture and agency. In C. Parker \& V. Nielsen (Eds.), Explaining compliance: Business responses to regulation. Cheltenham: Edward Elgar.

Parker, C., \& Nielsen, V. (2009a). The challenge of empirical research on business compliance in regulatory capitalism. Annual Review of Law and Social Science, 5, 45-70.

Parker, C., \& Nielsen, V. (2009b). Deterrence and the impact of calculative thinking on business compliance with regulation. The Antitrust Bulletin, 56(2), 377-426.

Parker, C., \& Nielsen, V. L. (2009c). Corporate compliance systems could they make any difference? Administration \& Society, 41(1), 3-37.

Prakash, A. (2001). Why do firms adopt 'beyond-compliance' environmental policies? Business Strategy and the Environment, 10(5), 286-299.

Ragin, C. C. (1987). The comparative method, moving beyond qualitative and quantitative strategies. Berkeley, CA: University of California Press.

Riggs, F. W. (1964). Administration in developing countries, the theory of the prismatic society. Boston: Houghton Mifflin Company.

Rooij, V., Benjamin, A. F., Yanyan, Z., \& Yunmei, W. (2017). Comparative compliance: Digital piracy, deterrence, social norms and duty in China and the United States. Law \& Policy, 39(1), 73-93.
Rorie, M., Simpson, S. S., \& Boppre, B. (2018). Factorial survey research in the study of environmental regulatory processes. In W. H. van Boom, P. Desmet, \& P. Mascini (Eds.), Empirical legal research in action (pp. 137-172). London: Edward Elgar.

Seawright, J., \& Gerring, J. (2008). Case selection techniques in case study research: A menu of qualitative and quantitative options. Political Research Quarterly, 61(2), 294-308.

Short, J. L., \& Toffel, M. W. (2008). Coerced confessions: Self-policing in the shadow of the regulator. Journal of Law Economics and Organization, 24(1), 45-71.

Simpson, S., Rorie, M., Alper, M. E., Schell-Busey, N., Laufer, W., \& Smith, N. C. (2014). Corporate crime deterrence: A systematic review. Campbell Systematic Reviews, 10(4), 105. https://doi. org/10.4073/csr.2014.4.

Talesh, S. A. (2009). The privatization of public legal rights: How manufacturers construct the meaning of consumer law. Law \& Society Review, 43(3), 527-562.

Talesh, S. (2015). Rule-intermediaries in action: How state and business stakeholders influence the meaning of consumer rights in regulatory governance arrangements. Law \& Policy, 37(1-2), 1-31.

Thornton, D., Gunningham, N., \& Kagan, R. A. (2005). General deterrence and corporate environmental behavior. Law \& Policy, 27(2), 262-288.

Tyler, T. R. (1997). Procedural fairness and compliance with the law. Swiss Journal of Economics and Statistics, 133(2), 219-240.

Tyler, T. R. (2006). Why people obey the law. Princeton: Princeton University Press.

Tyler, T. R., \& Darley, J. M. (1999). Building a law-abiding society: Taking public views about morality and the legitimacy of legal authorities into account when formulating substantive law. Hofstra L. Review, 28, 707.

Ubink, J. M. (2008). Negotiated or negated? The rhetoric and reality of customary tenure in an Ashanti village in Ghana. Africa, 78(2), 264-287.

Van Erp, J. (2008). Reputational sanctions in private and public regulation. Erasmus Law Review, 1(5), 145.

Van Erp, J. (2011). Naming without shaming: The publication of sanctions in the Dutch financial market. Regulation \& Governance, 5(3), 287-308

van Gelder, J. L., \& de Vries, R. E. (2013). Rational misbehavior? Evaluating an integrated dual-process model of criminal decision making. Journal of Quantitative Criminology, 30(1), 1-27.

Van Rooij, B. (2006). Regulating land and pollution in China, lawmaking, compliance, and enforcement; theory and cases. Leiden: Leiden University Press.

Van Rooij, B. (2012). Compliance: Understanding legal and social approaches. In H. Jiang \& Z. Wang (Eds.), Compliance, the new development trend of global companies (pp. 102-117). Beijing: China Economic Publishing House.

Vaughan, D. (1989). Regulating risk: Implications of the challenger accident*. Law \& Policy, 11(3), 330-349.

Vaughan, D. (1997). The challenger launch decision: Risky technology, culture, and deviance at NASA. Chicago: University of Chicago Press.

Von Benda-Beckmann, F. (2006). The multiple edges of law: Dealing with legal pluralism in development practice. In C. Sage \& M. Woolcock (Eds.), The world bank legal review: Law, equity, and development (pp. 51-86). Washington DC: Martinus Nijhoff.

Wenzel, M. (2005). Motivation or rationalisation? Causal relations between ethics, norms and tax compliance. Journal of Economic Psychology, 26(4), 491-508.

Publisher's Note Springer Nature remains neutral with regard to jurisdictional claims in published maps and institutional affiliations. 